\title{
ERCP in Total Situs Viscerum
}

\section{Inversus}

\author{
F. Fiocca G. Donatelli V.Ceci F. Cereatti F. Romagnoli \\ L. Simonelli C. Modini
}

Department of Emergency and Urgency, Policlinico Umberto I, University

'La Sapienza', Rome, Italy

\section{Key Words}

Total situs viscerum inversus - ERCP - Endoscopic sphincterotomy · Bile duct stones

\begin{abstract}
A 69-year-old cholecystectomized female with known total situs viscerum inversus presented recurrent colicky pain in the left upper abdominal quadrant and jaundice. Laboratory parameters showed increased neutrophils and coniugated bilirubin of 5.53 $\mathrm{mg} / \mathrm{dl}$. US and MRCP confirmed total situs viscerum inversus and a dilatation of the intraand extrahepatic ducts with a peripapillary $13 \mathrm{~mm}$ stone. ERCP, sphincterotomy and successful common bile duct stone extraction were performed in the conventional way. ERCP was carried out successfully despite situs inversus maintaining the patient in the prone position with the endoscopist on the right side of the table. Some authors have reported similar cases in whom ERCP was performed in other positions, while this report shows that an experienced endoscopist can achieve the same results in the conventional way as it is possible when anatomical changes, Billroth II or Roux-en-Y, or different positions of the patient, supine or on the left side, are present.
\end{abstract}

\section{Introduction}

Situs viscerum inversus is a rare condition with a genetic predisposition, with a frequency of 1:5,000 to 1:10,000 live births, in which the organs are transposed, totally or partially, to the opposite side of the body. In total situs inversus there is a complete transposition of all viscera, dextroposition of the heart, and the liver is palpable in the left upper quadrant [1].

Endoscopic sphincterotomy and stone extraction are standard procedures for the removal of bile duct stones. The instrumentation, the side view endoscope, is built for the right position of the liver with the papilla at the medial side of the duodenum. 
We report the case of a 69 -year-old female, cholecystectomized, with choledocholithiasis and total situs inversus, in whom an ERCP was performed with sphincterotomy and bile duct stone extraction.

\section{Case Report}

A 69-year-old white female with known total situs viscerum inversus, with previous cholecystectomy, right radical nephrectomy, polycystic disease of the left kidney, hemodialyzed, presented to our emergency department with colicky pain located to the abdominal left upper quadrant with irradiation toward the subscapular region and upward to the left shoulder. The pain had started $24 \mathrm{~h}$ earlier and was associated with nausea, vomiting, fever $\left(38.5^{\circ} \mathrm{C}\right)$ and jaundice.

Physical examination revealed pronounced tenderness on the left hypochondrium, polycystic kidney and decreased bowel sounds. The edge of the liver was soft and palpable two fingers below the left costal margin on deep inspiration.

Laboratory studies showed: white cell count 15,500/ml (n. 4,000-10,000); total bilirubin $5.88 \mathrm{mg} / \mathrm{dl}$ with direct fraction of $5.53 \mathrm{mg} / \mathrm{dl}$; AST $119 \mathrm{U} / \mathrm{l}$; ALT $130 \mathrm{U} / \mathrm{l}$; amylase $357 \mathrm{U} / \mathrm{dl}$; lipase 1,535 U/dl; alkaline phosphatase $845 \mathrm{U} / \mathrm{dl}$; gamma-GT $685 \mathrm{U} / \mathrm{dl}$; creatinine $2.5 \mathrm{mg} / \mathrm{dl}$; BUN $78 \mathrm{mg} / \mathrm{dl}$. All other laboratory parameters were in the normal range. Abdominal ultrasound (US) confirmed the situs viscerum inversus and showed a dilatation of the intra- and extrahepatic bile duct with a stone in the common duct.

The diagnosis was cholangitis with edematous pancreatitis. The patient was admitted to the hospital and antibiotics therapy (piperacillin $2 \mathrm{~g} \times 3$ i.v.) and infusional therapy was started. Hemodialysis sessions were carried out as scheduled. On the following days a general improvement was noted and all laboratory values came back within normal limits.

A magnetic resonance cholangiopancreatography demonstrated a $1.3 \mathrm{~cm}$ peripapillary stone with the common bile duct dilated to $1.5 \mathrm{~cm}$ (ig. 1 ) and total situs viscerum inversus. Four days after admission, the patient underwent a therapeutic ERCP with sphincterotomy and stone extraction.

After premedication with pharyngeal xilocaine $10 \%$ and conscious sedation with diazepam $5 \mathrm{mg}$, duodenoscopy was performed with a lateral-view endoscope (Olympus TJF-30). The patient was in the usual prone position with the endoscopist at the right side of the table. In the stomach the endoscope was turned 180 degrees to the right and, under fluoroscopic control, the second portion of the duodenum was reached (fig. 2): another 180 degrees tortion towards the right was necessary and pushing against the duodenal wall the papilla was maintained in the correct position retrieving the instrument in the short position, diminishing the torsion of the instrument. The ERCP was carried out in the usual way with a long-nose cannulotome (Boston Scientific).

The cholangiography confirmed the dilatation of the common bile duct up to $16 \mathrm{~mm}$ with an impacted stone of $15 \mathrm{~mm}$ (fig. 3 ). After a standard sphincterotomy the stone was removed with a Dormia basket. The procedure lasted $35 \mathrm{~min}$.

The postoperative course was uneventfull, pancreatic enzymes remained within the normal range and the patient was discharged after two days.

\section{Discussion}

The current treatment for choledocholithiasis is endoscopic sphincterotomy followed by stone extraction. Therapeutic ERCP for bile duct stones has a success rate of $96-100 \%$ [2]. The standard position for ERCP is the left lateral or prone one. This is preferred because it allows a better delineation of the biliary and pancreatic duct anatomy [2]. Biliary cannulation has a success rate of almost $100 \%$ with the patients in the prone position [4]. Many reports showed that the supine position does not affect the feasibility of ERCP when the operator turns the instrument clockwise 180 degrees [5]. 


\begin{tabular}{c|l|l|l}
$\begin{array}{c}\text { Case Reports in } \\
\text { Gastroenterology }\end{array}$ & $\begin{array}{l}\text { Case Rep Gastroenterol 2008;2:116-120 } \\
\text { Dol: 10.1159/000119713 }\end{array}$ & Published online: March 14, 2008 & $\begin{array}{l}\text { @ 2008 S. Karger AG, Basel } \\
\text { ISSN 1662-0631 } \\
\text { www.karger.com/crg }\end{array}$ \\
\hline
\end{tabular}

ERCP can be technically challenging because of anatomic variants, when operative alteration are carried out on the upper digestive system (such as Billroth I, Billroth II gastric resection, Roux-en- $Y$ enteroanastomosis etc.), and in case of pathological changes [2]. Endoscopic access to the papilla is $92 \%$ in Billroth II and 33\% in Roux-en-Y reconstructions [5].

Fabricius described for the first time situs viscerum inversus in humans. The exact etiology remains obscure, but attempts have been made to explain it on the basis of a complex gene with variable expression [3].

Pathak et al. [3] reported a case of ERCP performed in situs viscerum inversus keeping the patient in the prone position and the endoscopist at the left side. However, extrarotation of the instrument, this time counterclockwise, was necessary as the instrument is built with the side view. We succeeded to pass the stomach and to reach the duodenum with only a 180 degrees turn and the correct position was maintained pushing the second portion of the duodenum as it happens reaching the papilla in the Billroth II patient. The X-ray showed the position of the endoscope quite similar to that obtained in the Billroth II patient, naturally on the other side (fig. 3).

In conclusion, this report shows that in expert hands it is possible to perform ERCP in every anatomical condition, also in patients with situs viscerum inversus.

Fig. 1. MRI: dilated common bile duct with impacted stone $1.3 \mathrm{~cm}$, polycystic left kidney.

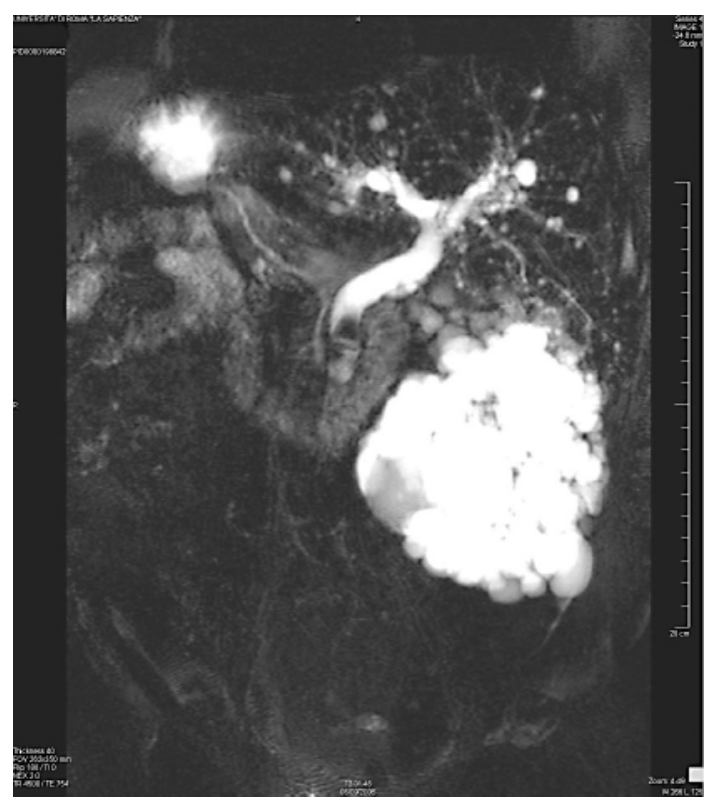


Fig. 2. Control of the position of the side-view endoscope in the second duodenal portion.

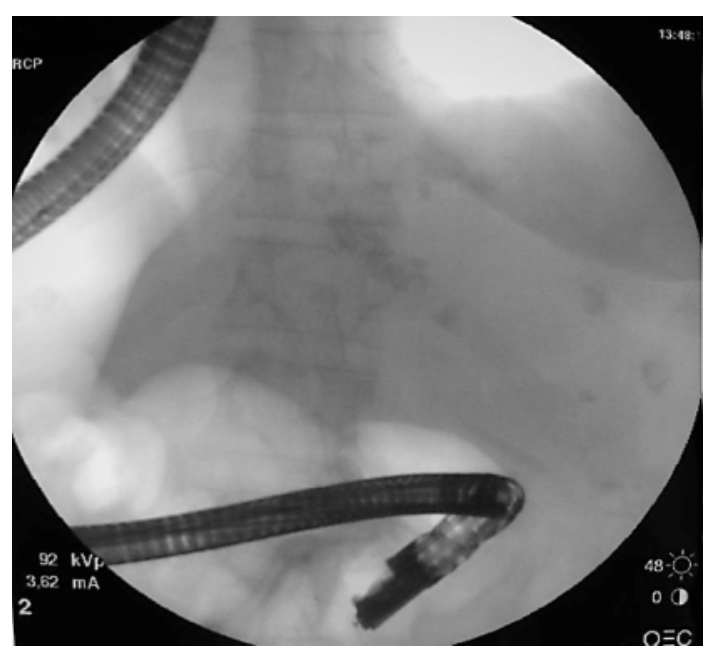

Fig. 3. a Cholangiography and common bile duct cannulation with the instrument in the short position. b Stone extraction with Dormia basket.
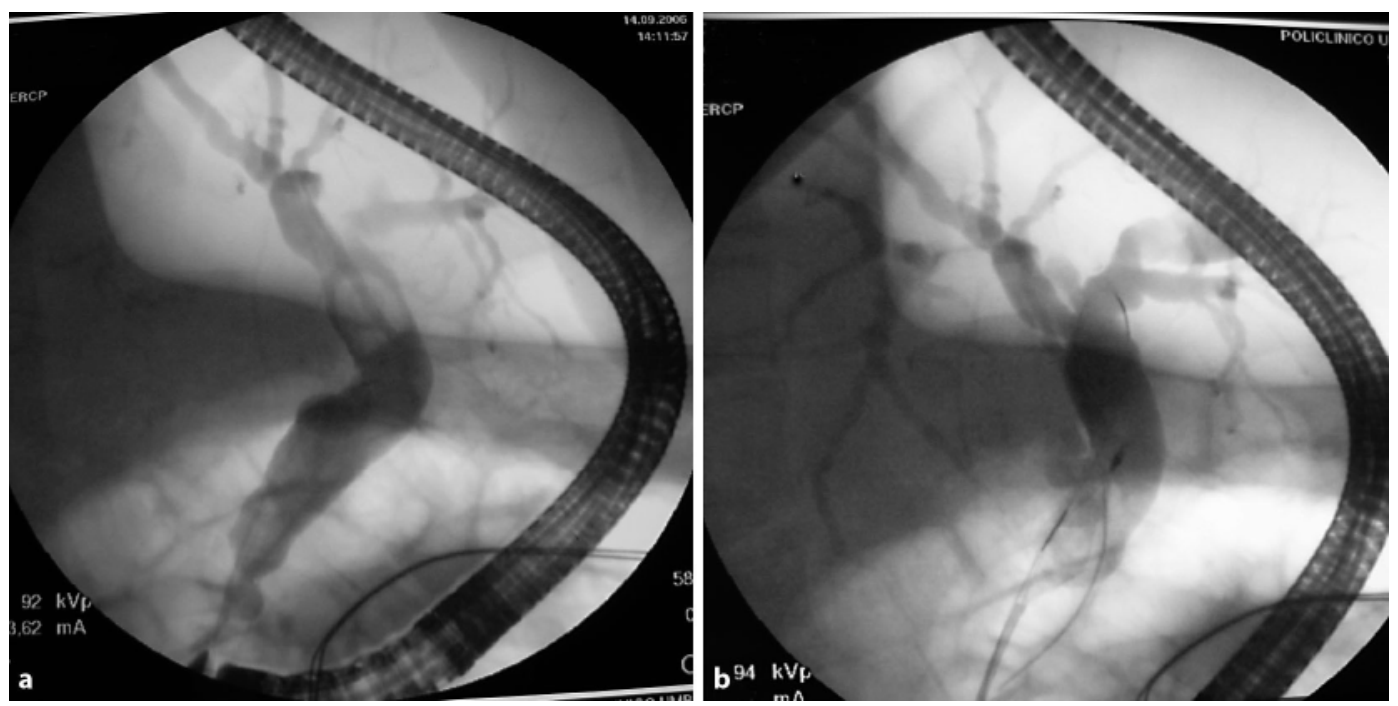


\section{References}

1 Gastrointestinal: situs inversus viscerum. J Gastroenterol Hepatol 2002;17:1329.

2 Therapeutic Endoscopy. Color Atlas of Operative Techniques for the Gastrointestinal Tract. Berlin, Thieme, 2005, p 88.

3 Pathak KA, Khanna R, Khanna N: Situs inversus with cholelithiasis. J Postgrad Med 1995;41:45-46.

4 Terruzzi V, Radaelli F, Meucci G, Minoli G: Is the supine position as safe and effective as the prone position for endoscopic retrograde cholangiopancreatography? A prospective randomized study. Endoscopy 2005;37:1211-1214

5 Hintze RE, Adler A, Veltzke W, Abou-Rebyeh H: Endoscopic access to the papilla of Vater for endoscopic retrograde cholangiopancreatography in patients with Billroth II and Roux-en-Y gastrojejunostomy. Endoscopy 1997;29:69-73. 